\title{
PENGARUH PENYULUHAN DAN PELATIHAN MELALUI MEDIA LEAFLET TERHADAP PENGETAHUAN KADER PHBS DI KECAMATAN RATOLINDO KABUPATEN TOJO UNA-UNA
}

\author{
The Effect Of Extension And Training Through Leaflet Media On Knowledge \\ of PHBS Kader In Kecamatan Ratolindo Kabupaten Tojo Una-Una
}

\author{
Azizah Saleh ${ }^{1}$, Firdaus J. Kunoli ${ }^{2}$ \\ 1Prodi D-III Keperawatan, Jurusan Keperawatan Poltekkes Kemenkes Palu \\ (hj.azizahsaleh07@gmail.com) \\ 2 Prodi D-IV Keperawatan, Jurusan Keperawatan Poltekkes Kemenkes Palu \\ (kunolifirdaus@gmail.com)
}

\begin{abstract}
ABSTRAK
Masih rendahnya cakupan Perilaku Hidup Bersih Dan Sehat (PHBS) dan belum banyak masyarakat yang benar-benar menerapkan PHBS. Di kecamatan Ratolindo, untuk itulah perlu dilakukan peningkatan pengetahuan keluarga dan pembinaan kader dengan memberikan penyuluhan.dan latihan pemberdayaan. Tujuan penelitian ini adalah untuk mengetahui pengaruh efektifitas Penyuluhan dan pelatihan melalui media Leaflet terhadap pengetahuan Kader PHBS Di Kecamatan Ratolindo Kabupaten Tojo Una-una tahun 2017. Penelitian ini menggunakan desain penelitian quasi eksperimental dengan quasiexperimental one group pretest-posttest design. Pengukuran dilakukan sebelum dan setelah pemberian penyuluhan kesehatan dan pembinaan kader tentang konsep PHBS dengan metode leaflet.Dengan jumlah sampel sebanyak 40 sampel. Analisis data dengan menggunakan program SPSS, dan dilakukan uji normalitas. Uji hipotesis yang digunakan dalam penelitian ini adalah independent sample t-test, paired ttest. Hasil penelitian ini menunjukan bahwa terdapat perbedaan rata-rata frekuensi pengetahuan kader PHBS setelah dilakukan intervensi penyuluhan dan pelatihan, Hasil Uji Paired Sample t test diperoleh nilai signifikan dengan nilai $\rho$ Value $=0.010$. bahwa ada pengaruh penyuluhan dan pelatihan melalui media Leaflet terhadap pengetahuan Kader PHBS Di Kecamatan Ratolindo Kabupaten Tojo Una-una tahun 2017. Pada hasil analisis univariat diperoleh hasil pengetahuan kader PHBS mengalami peningkatan peningkatan walaupun masih ada sebagian yang dari kader PHBS yang memiliki pengetahuan rendah.
\end{abstract}

Kata Kunci : Penyuluh, pelatihan, media leaflet, pengetahuan kader

\section{ABSTRACT}

The low coverage of Clean and Healthy Life Behavior (PHBS) and not many people actually implement PHBS. for example childbirth assistance. In Ratolindo sub-district, for this reason it is necessary to increase family knowledge and coaching cadres by providing education and empowerment exercises. The purpose of this study was to determine the effect of the effectiveness of counseling and training through media leaflets on the knowledge of PHBS cadres in Ratolindo Subdistrict Tojo Una-Una District in 2017. This study used a quasi-experimental research design with quasi-experimental one group pretest-posttest design. Measurements were made before and after the provision of health counseling and coaching of cadres about the concept of PHBS using the leaflet method. The number of samples was 40 samples. Data analysis using the SPSS program, and normality tests were carried out. The hypotheses used in this study were independent sample t-test, paired $t$-test. The results of this study indicate that there are differences in the average frequency of knowledge of PHBS cadres after counseling and training interventions, Paired Sample t test results obtained a significant value with a value of $\rho$ Value $=0.010$. that there is an influence of counseling and training through media Leaflets on the knowledge of PHBS Cadres in Ratolindo Subdistrict Tojo Una-Una District in 2017. The results of univariate analysis showed that the knowledge of PHBS cadres increased despite the fact that there were still some who had low knowledge of PHBS cadres.

Keywords : Counseling, Training, Media leaflets and Knowledge Cadres

\footnotetext{
Sekretariat

Editorial: Kampus FKM UNISMUH PALU - Palu 94118, Sulawesi Tengah, Indonesia

Telp/HP: +6281245936241, Fax (0451) 425627

E-mail: jurnal.mppki@gmail.com

OJS: http://jurnal.unismuhpalu.ac.id/index.php/PJKM
}

\author{
Article History: \\ $\Rightarrow \quad$ Received 10 September 2018 \\ $\Rightarrow \quad$ Revised 07 Oktober 2018 \\ $\Rightarrow \quad$ Accepted 24 November 2018 \\ $\Rightarrow \quad$ Available online 31 Desember 2018
}




\section{PENDAHULUAN}

Kualitas sumber daya manusia (SDM) antara lain ditentukan dua faktor yang satu sama lain saling berhubungan, berkaitan dan saling bergantung yakni pendidikan dan kesehatan. Kesehatan merupakan prasyarat utama agar upaya pendidikan berhasil, sebaliknya pendidikan yang diperoleh akan sangat mendukung tercapainya peningkatan status kesehatan seseorang (Depkes, R.I.,2009)

Untuk mencapai sasaran pembangunan kesehatan dan juga dengan mempertimbangkan perkembangan, masalah, serta berbagai kecenderungan pembangunan kesehatan ke depan, maka Kementrian Kesehatan menetapkan visi tentang "Masyarakat Sehat yang Mandiri dan Berkeadilan". Dalam hal ini, derajat kesehatan masyarakat ditingkatkan melalui pemberdayaan masyarakat itu sendiri sehingga masyarakat dapat dengan mandiri meningkatkan derajat kesehatannya. Selain itu, upaya ini juga didukung dengan meningktakan pelayanan kesehatan yang bermutu dam berkeadilan (Depkes R.I., 2010)

Program promosi perilaku hidup bersih dan sehat yang biasa dikenal PHBS merupakan pendekatan terencana untuk mencegah penyakit menular. Program ini dimulai dengan apa yang diketahui, diinginkan dan dilakukan masyarakat setempat dan mengembangkan program berdasarkan informasi tersebut (Depkes RI, 2007).

Program promosi PHBS harus dilakukan secara profesional oleh individu dan kelompok yang mempunyai kemampuan dan komitmen terhadap kesehatan masyarakat serta memahami tentang lingkungan dan mampu melaksanakan komunikasi, edukasi dan menyampaikan informasi secara tepat dan benar yang sekarang disebut dengan promosi kesehatan.Tenaga kesehatan masyarakat diharapkan mampu mengambil bagian dalam promosi PHBS sehingga dapat melakukan perubahan perilaku masyarakat untuk hidup berdasarkan PHBS.Tenaga kesehatan masyarakat telah mempunyai bekal yang cukup untuk dikembangkan dan pada waktunya disumbangkan kepada masyarakat dimana mereka bekerja (Depkes RI, 2007).
Dalam mewujudkan PHBS secara terencana, tepat berdasarkan situasi daerah maka diperlukan pemahaman dan tahapan Memperkenalkan kepada masyarakat gagasan dan teknik perilaku Program Perilaku Hidup Bersih dan Sehat (PHBS), yang merupakan pendekatan terencana untuk mencegah penyakit diare melalui pengadopsian perubahan perilaku oleh masyarakat secara meluas. Program ini dimulai dari apa yang diketahui, diinginkan, dan dilakukan masyarakat. Perencanaan suatu program promosi hygiene untuk masyarakat dilakukan berdasarkan jawaban atau pertanyaan diatas atau bekerjasama dengan pihak yang terlibat, untuk itu diperlukan pesan-pesan sederhana, positif, menarik yang dirancang untuk dikomunikasikan lewat sarana lokal seperti poster, leaflet (Depkes RI, 2007).

Mengidentifikasikan perubahan perilaku masyarakat, dalam tahap ini akan dilakukan identifikasi perilaku beresiko melalui pengamatan terstruktur. Sehingga dapat ditentukan cara pendekatan baru terhadap perbaikan hygiene sehingga diharapkan anak-anak terhindar dari lingkungan yang terkontaminasi (Depkes RI, 2007).

Sasaran PHBS tidak hanya terbatas tentang hygiene, namun harus lebih komprehensif dan luas, mencakup perubahan lingkungan fisik, lingkungan biologi dan lingkungan sosial -budaya masyarakat sehingga tercipta lingkungan yang berwawasan kesehatan dan perubahan perilaku hidup bersih dan sehat.Lingkungan fisik seperti sanitasi dan hygiene perorangan, keluarga dan masyarakat, tersedianya air bersih, lingkungan perumahan, fasilitas mandi, cuci dan kakus (MCK) dan pembuangan sampah serta limbah.Lingkungan biologi adalah flora dan fauna.Lingkungan sosial-budaya seperti pengetahuan, sikap perilaku dan budaya setempat yang berhubungan dengan PHBS (Depkes RI, 2007).

Menerapkan Pelaku Hidup Bersih dan Sehat (PHBS) merupakan langkah ampuh untuk menangkal penyakit.Tidak hanya itu, beberapa pakar juga berpendapat bahwa penerapan konsep PHBS juga mampu membebaskan pemerintah dari masalah kesehatan dan ekonomi kesehatan.Sayangnya dalam praktiknya, penerapan PHBS yang kesannya sederhana tidak selalu mudah dilakukan.Terutama bagi mereka yang tidak terbiasa.Dalam hal ini, 
pendidikan dari keluarga sangat dibutuhkan (Thary, 2009).

Perilaku Hidup Bersihdan Sehat (PHBS) tersebut harus dimulai dari tatanan rumah tangga, karena rumah tangga yang sehat merupakan aset modal pembangunan dimasa depan yang perlu dijaga, ditingkatkan dan dilindungi kesehatannya. Beberapa anggota rumah tangga mempunyai masa rawan terkena penyakit infeksi dan non infeksi, oleh karena itu untuk mencegahnya anggota rumah tangga perlu diberdayakan untuk melaksanakan Perilaku Hidup Bersih dan Sehat(PHBS) (Depkes RI, 2009).

Keluarga merupakan unit terkecil dari suatu bangsa. Didalam keluarga terjadi interaksi dan komunikasi antara anggota keluarga yang menjadi awal penting dari suatu proses pendidikan. Ditanamkannya PHBS sejak dini dalam keluarga dapat menciptakan keluarga yang sehat. Keluarga yang sehat akan membentuk masyarakat desa, kelurahan, kecamatan, kabupaten, provinsi dan bangsa yang sehat.

Penerapan perilaku hidup bersih sehat (PHBS) terdapat faktor-faktor yang mempengaruhi.Lawrence Green dalam Notoadmodjo (2010), membedakan adanya dua determinan masalah kesehatanya itu factor perilaku (behavioral factors) dan faktor non perilaku (non behavioralfactors). Green menjelaskan bahwa factor perilaku ditentukan oleh tiga factor utama yaitu factor predisposisi, factor pendukung atau pemungkin dan factor penguat. Faktor predisposisi yaitu terjadinyaperilakuseseorangantaralainpengetah uan, sikap, persepsi, keyakinan, kepercayaandanjuganila-nilaitradisi. Sedangkan factor pemungkin yaitu Hubungan antarakonsep pengetahuan dan praktek. Dan faktor penguat yang mendorong untuk bertindak untuk mencapai suatu tujuan yang terwujud dalam peran keluarga terutama orang tua, kader kesehatan dan petugas kesehatan.

Pengetahuan merupakan domain yang sangat penting untuk terbetuknya perilaku sesesorang (over behavior), karena prilaku yang didasari oleh pengetahuan akan lebih langgeng dari prilaku yang tidak didasari oleh pengetahuan (Notoadmodjo, 2007).

Berdasarkan informasi dari Puskesmas Ampana Timur masyarakat di kecamatan Ratolindo masih rendah cakupan Perilaku Hidup Bersih Dan Sehat (PHBS) dan belum banyak masyarakat yang benar-benar menerapkan PHBS. misalnya pertolongan persalinan. Pemberian ASI eksklusif masih rendah, merokok dalam rumah, dll.

Untuk itulah perlu dilakukan peningkatan pengetahuan keluarga dan pembinaan kader dengan memberikan penyuluhan.dan latihan pemberdayaan tentang bagaimana menerapkan perilaku hidup bersih dan sehat diwilayah kerja Puskesmas Ampana Timur, Kecamatan Ratolindo Kabupaten Tojo Una-Una.

Tujuan penelitian adalah diketahuinya pengaruh penyuluhan dan pelatihan melalui media Leaflet terhadap pengetahuan Kader PHBS Di Kecamatan Ratolindo Kabupaten Tojo Una-una

\section{BAHAN DAN METODE}

Penelitian ini menggunakan desain penelitian quasi eksperimental dengan quasi-experimental one group pretest-posttest design yaitu penelitian yang menggunakan satu kelompok subyek. Pengukuran dilakukan sebelum dan setelah pemberian penyuluhan kesehatan dan pembinaan kader tentang konsep PHBS dengan metode leaflet.Dengan jumlah sampel sebanyak 40 sampel. Analisis data menggunakan Uji independent sample t-test, paired t-test.

\section{HASIL}

Tabel 1, Berdasarkan hasil analisis menunjukan bahwa responden yang berpengetahuan rendah sebanyak 20 responden $(50 \%)$ dan responden berpengetahuan tinggi sebanyak 20 responden (50\%).

Tabel 2, Berdasarkan hasil analisis menunjukan bahwa responden yang berpengetahuan rendah sebanyak 10 responden $(25 \%)$ dan responden berpengetahuan tinggi sebanyak 30 responden (75\%).

Tabel 3, Hasil uji statistik menunjukan rata-rata pengetahuan kader sebesar - .275 terlihat bahwa terdapat perbedaan ratarata frekuensi pengetahuan kader PHBS setelah dilakukan intervensi penyuluhan dan pelatihan, Hasil Uji Paired Sample T test dengan tingkat kemaknaan $(\alpha=0,05)$ diperoleh nilai signifikan dengan nilai $\rho$ Value $=0.010$. maka disimpulkan bahwa ada pengaruh efektifitas Penyuluhan dan pelatihan melalui media Leaflet terhadap pengetahuan Kader PHBS Di Kecamatan Ratolin- 
do Kabupaten Tojo Una-una tahun 2017. Pada hasil analisis univariat diperoleh hasil pengetahuan kader PHBS mengalami peningkatan peningkatan walaupun masih ada sebagian yang dari kader PHBS yang memiliki pengetahuan rendah dengan proporsi $25 \%$.

\section{PEMBAHASAN}

Hasil penelitian univariat memperlihatkan bahwa pengetahuan kader PHBS mengalami peningkatan peningkatan walaupun masih ada sebagian yang dari kader PHBS yang memiliki pengetahuan rendah dengan proporsi $25 \%$.. Hasil Uji statistik $\mathrm{t}$ test menunjukan bahwa terdapat perbedaan rata-rata frekuensi pengetahuan kader PHBS setelah dilakukan intervensi penyuluhan dan pelatihan dengan nilai $\rho$ Value $=$ 0.010

Menurut asumsi peneliti bahwa pemberian pengetahuan melalui penyuluhan dan pelatihan dengan kombinasi media leaflet sangat berpengaruh terhadap perubaan pengetahuan kader PHBS hal ini terlihat dari hasil analisis univariat setelah diberikan penyuluhan dan pelatihan dengan menggunakan media leaflet terdapat peningkatan pengetahuan. Hasil uji statistik membuktikan bahwa ada perbedaan pengetahuan sebelum dan setelah diberikan intervensi penyuluhan dan pelatihan. Selain itu Kader PHBS di wilayah kerja Puskesmas Ampana Timur sangat aktif dalam kegiatan posyandu dimana sebagian besar kader PHBS adalah merupakan kader Posyandu sehingga responden sering berinteraksi dan menerima informasi dengan petugas kesehatan dari Puskesmas.

Penelitian yang dikemukakan oleh Lubis dkk (2013) bahwa peningkatan dengan metode ceramah pada responden ini disebabkan karena intervensi yang diberikan kepada responden sehingga dapat membantu responden meningkatkan pengetahuan dan sikapnya tentang PHBS, dari hasil pre-test dan post-test dapat dikatakan bahwa pengetahuan dan sikap responden setelah diberikan penyuluhan dengan metode ceramah mengalami peningkatan. Penyuluhan menurut Machfoedz (2009) sebagaikegiatan pendidikan kesehatan yang dilakukan dengan menyebar pe- san,menanamkan keyakinan, sehingga masyarakat tidak hanya sadar, tahu danmengerti, tetapi juga mau dan bisa melakukan suatu anjuran yang adahubungannya dengan kesehatan.

Sosialisasi PHBS adalah upaya untuk memberikan pengalaman belajar atau menciptakan suatu kondisi bagi perorangan, keluarga, kelompok dan masyarakat, dengan membuka jalur komunikasi, memberikan informasi dan melakukan edukasi, untuk meningkatkan pengetahuan, sikap dan perilaku, melalui pendekatan pimpinan (Advokasi), bina suasana (Social Support) dan pemberdayaan masyarakat (Empowerment). Dengan demikian masyarakat dapat mengenali dan mengatasi masalahnya sendiri, terutama dalam tatanan masing-masing, dan masyarakat/dapat menerapkan cara-cara hidup sehat dengan menjaga, memelihara dan meningkatkan kesehatannya

\section{KESIMPULAN DAN SARAN}

Hasil penelitian univariat memperlihatkan bahwa pengetahuan kader PHBS mengalami peningkatan setelah diberikan intervensi dalam bentuk penyuluhan dan pelatihan melalui media leaflet. Hasil Uji statistik $t$ test menunjukan bahwa terdapat perbedaan rata-rata frekuensi pengetahuan kader PHBS setelah dilakukan intervensi penyuluhan dan pelatihan dengan nilai $\rho$ Value $=0.010$. Saran dalam penelitian ini adalah Diharapkan bagi pihak Puskesmas, khususnya bagian Promosi Kesehatan Puskesmas Ampana Timur untuk selalu mensosialisasikan program PHBS kepada kader dan masyarakat sehingga masyarakat mendapatkan informasi tentang penting dan manfaat PHBS

\section{DAFTAR PUSTAKA}

Departemen Kesehatan RI. Pusat Promosi Kesehatan. Panduan Pelatihan Komunikasi Perubahan Perilaku, Untuk KIBBLA,J akarta 2008

Depkes R.I. 2009. Peningkatan Perilaku Hidup Bersih dan Sehat Di Rumah Tangga. Jakarta.

Depkes R.I. 2010, Visi Depkes 2010 - 2010 http://dinkeslampung.com. html. diakses tanggal 10 Nopember 2016

Depkes RI. 2007. Perilaku Hidup Bersih Dan Sehat. Jakarta. 
Edy Sukiarto. 2007. Pengaruh pelatihan dengan metode belajar berdasarkan masalah terhadap pengetahuan dan keterampilan kader gizi dalamKegiatan posyandu. Tesis Program Pasca sarjan Univesitas Diponegoro, Semarang, Jurnal Kesehatan, diakses tanggal 14 Maret 2017.

Entjang I. 2000. Ilmu Kesehatan Masyarakat, Citra Aditya Bakti, Bandung

Ferri, Anton. 2008. Rumah Tangga Sehat. socialmedia phbs, www.google.com, diakses tanggal 10 Nopember 2016

Lameshow, H., 1997. Besar Sampel Dalam Penelitian Kesehatan, Yogyakarta, Gajah Mada University Press

Lubis ASZ, Lubis LN, dan Syahrial E. 2013. Pengaruh Penyuluhan Dengan Metode Ceramah dan Diskusi Terhadap Peningkatan Pengetahuan dan Sikap Anak Tentang PHBS Di SD Negeri 065014 Kelurahan Namogajah Kecamatan Medan Tuntungan Tahun 2013. Jurnal Ilmiah. Fakultas Ilmu Kesehatan Masyarakat Universitas Sumatra Utara.

Machfoedz I dan Suryani E. 2009. Pendidikan Kesehatan Bagian Dari Promosi Kesehatan. Fitramaya, Yogyakarta.

Notoatmodjo. 2010. Ilmu Perilaku Kesehatan, Rineka Cipta, Jakarta.

Notoatmodjo. 2012. Metodologi Penelitian Kesehatan. PT. Rineka Cipta, Jakarta.

Notoatmodjo. 2012. Promosi Kesehatan Dan Perilaku Kesehatan. Edisi Revisi, Rineka Cipta, Jakarta.

Sugiyono. 2002. Statistik Untuk Penelitian, Cetakan ke tiga, Alfabeta, Bandung.

Thary. 2009. PHBS Wujud Awal Bangsa Sehat. Majalah Dokter Kita Edisi IV, http// www.goggle.co.id, diakses tanggal 10 Nopember 2016

Wastuwibowo. 2008. 15 Masalah Kesehatan Anak Di Sekolah dan PHBS http// dinkes.bontangkota.go.id/index.php/ informasi-kesehatan/15 masalah kesehatan -anak-sekolah-danphbs.html. diakses tanggal 10 Nopember 2016 


\section{LAMPIRAN}

Tabel 1. Distribusi Tingkat Pengetahuan Sebelum DiBerikan Penyuluhan Dan Pelatihan PHBS Di Kecamatan Ratolindo

\begin{tabular}{ccc}
\hline Pengetahuan & F & \% \\
\hline Rendah & 20 & 50 \\
Tinggi & 20 & 50 \\
\hline Total & $\mathbf{4 0}$ & $\mathbf{1 0 0}$ \\
\hline
\end{tabular}

Sumber: Data Primer yang diolah

Tabel 2. Distribusi Tingkat Pengetahuan Setelah DiBerikan Penyuluhan Dan Pelatihan PHBS Di Kecamatan Ratolindo

\begin{tabular}{ccc}
\hline Pengetahuan & F & \% \\
\hline Rendah & 10 & 25 \\
Tinggi & 30 & 75 \\
\hline Total & $\mathbf{4 0}$ & $\mathbf{1 0 0}$
\end{tabular}

Sumber: Data Primer yang diolah

Tabel 3. Perbedaan Pengetahuan Sebelum dan Setelah diberikan Penyuluhan dan Pelatihan PHBS

\begin{tabular}{ccccc}
\hline & Mean & $\begin{array}{c}\text { Std. Devi- } \\
\text { ation }\end{array}$ & Std. Deviation & Sig. (2-tailed) \\
\hline Sebelum & -.275 & 0.640 & 0.101 & 0.010 \\
\hline
\end{tabular}

Sumber: Data Primer yang diolah 